\title{
Intelligent Prediction of the Daily Irrigation Water Requirements for Citrus Orchards Using FFNN with Levenberg Marquardt Algorithm
}

\author{
Olfa Marrakchi Charfi, Chiraz Masmoudi Charfi, Nizar Louhichi
}

\begin{abstract}
This paper describes an approach to predict the citrus water requirements using a Multi Layer Feed Forward Neural Network MLFFNN and the Levenberg-Marquardt Algorithm (LMA). Literature relates that the LMA is faster than the SONN and FFBP-NN algorithms. So the aim of this paper is focused on which best data base conception and the most performant MLFFNN architecture using LMA to predict water requierement for citrus plants in natural grow conditions.

The drip irrigated citrus orchards are grown at the Technical Centre of Citrus (CTA) of Nabeul, at Northeast of Tunisia $\left(36.5^{\circ} \mathrm{N}, 10.2^{\circ} \mathrm{E}\right)$, where trees are cultivated under standard conditions (disease-free, well-fertilized and not short of water). The daily climatic data (minimum and maximum air temperatures and relative humidity, wind speed, precipitation and solar radiation) recorded at the site of the experiment were used as inputs to the MLFFNN. Two secondary databases (DB) were used, both taken from the CTA's original database, to test the network, which has, for the case study, a single output: the amount of irrigation water needed by the citrus groves.

Several architectures of the MLFFNN have been tested. The selected network, named A1-MLFFNN is constituted by two hidden layers, each comprising 5 neurons. With the LMA, the implementation of the A1-MLFFNN provides rapid and accurate results. The LMA showed high performance expressed in terms of the convergence speed and the reliability of the MLFFNN and particularly when using the DB2 (original database private of the unavailable water days) which is the most robust, giving the lowest RMSE and the highest coefficient of correlation $(r=0.799)$, and thus, allowing a better estimation of the amounts of irrigation water.
\end{abstract}

Index Terms - MLFFNN, water requirement, citrus trees, model.

\section{INTRODUCTION}

Estimating water requirements of the perennial crops has always been a major priority for researchers, because it has a significant role in determining the crop yields and in optimizing the water consumption at field level. Basically, the crop water requirement is defined as the amount of water required by plants to compensate the evapotranspiration loss from the cropped field. As it is depend on both, the crop

Olfa Marrakchi Charfi, Carthage university, Department of Physic and Instrumentation, National High Institute of Applied Sciences and Technology (INSAT), Centre Urbain Nord, Box 676, 2080. Tunis, Tunisia, GREEN TEAM Laboratory (LR17AGR01). Phone/ Mobile :+21620111377

Chiraz Masmoudi Charfi, Sfax University, Olive Tree Institute, Unit of Tunis, Sis INRAT, 14 Avenue Hédi Karray, Ariana, Tunisia, Phone/ Mobile :+2162278005

Nizar Louhichi, Carthage university, Department of Physic and Instrumentation, National High Institute of Applied Sciences and Technology (INSAT), Centre Urbain Nord, Box 676, 2080. Tunis, Tunisia, Phone/ Mobile :+21655730961 characteristics and the climatic data, which are site-specific, a panel of experts developed a simplified way to deal with evapotranspiration dependence on climate by relating it to a standard reference evapotranspiration (ET0) by the crop coefficient: Kc, which is expressed as the ratio of ETc to ET0, or ETc $=$ Kc ET0 [2]. Smith et al. (1996) defined ET0 as 'the rate of ET from an hypothetical crop with an assumed crop height of $12 \mathrm{~cm}$, a fixed canopy resistance of $70 \mathrm{sm}-1$ and an albedo of 0.23 , closely resembling the ET from an extensive surface of the green grass of uniform height, actively growing, completely shading the ground and not short of water'. To determine ET0, large number of formulas [8] has been used during the 50 past years (1942-2005). Early methods [8] were based on temperature, relative humidity and solar radiation. The Penman original method (1963) is based on combination theory, involving simultaneous measurements of radiation, air temperature, air humidity and wind speed. All calculation procedures are described in Rana and Katerji (2000) and Habaieb and Masmoudi-Charfi (2003) and recently summarized in Sammis et al. (2011), including the FAO-Penman-Monteith (PM) formula [2], which became the American Society of Civil Engineers (ASCE) Standardized Reference ET equation and the current recommended one to compute the evapotranspiration of well watered crops. It overcomes the shortcomings of the previous methods and provides consistent values of ET0 over a wide range of climatic conditions [3]. However, although this formula is largely used to compute ET0 for irrigation management and yield prediction, it can generate errors and uncertainties in data measurements and/or in the simplifications made during the different steps of ET0 computation, which is a non-linear phenomenon, derived by several interacting climatic data and not practical to measure directly. With regard to these limitations and others, recent studies suggest the use of the Artificial Neural Networks (ANNs) to predict accurately and rapidly ET0. Kumar et al. (2002) developed a Multi Layer Feed Forward Neural Network (MLFFNN) to estimate the daily ET0 using six climatic parameters as inputs and compared the results with those computed directly by the FAO-56 PM method and with those measured by the lysimeter. Zanetti et al. (2007) developed an MLFFNN for the ET0 estimation by using the maximum and the minimum air temperatures as inputs and compared the generated performance with that obtained by the empirical temperature-based equations. Rahimikhoob (2010) developed temperature-based ANN models and compared his results with those obtained by the application of the Christiansen-Hargreaves and the FAO-56 PM equations. However, the use of the MLFFNN may present some limitations such as the long training time to provide a solution 
and the non guarantee of the convergence of the obtained results. To overcome these limitations, Adamala et al. (2014) developed a Second Order Neural Network (SONN) to estimate ET0 for different locations in India, providing more accurate results. They have focused their work on the use of a higher-order Neural Network in order to model ET0.

The main objective of this study is to provide an automatic prediction of the citrus water requirements grown on sandy or sand-clay soils in the Northeast of Tunisia by using the MLFFNN. The originality of this work is the use of the Levenberg-Marquardt algorithm for the adaptation of the syntactic weights of the MLFFNN, which proven its performance in similar studies. Through this work we would like to test and verify its performance under Tunisian conditions. The remaining of this paper is organized as follows: In the section 2, we present the methods and materials used; the section 3 presents the results obtained; the section 4 presents the discussions on these results; the section 5 presents the result validation, finally, the conclusion of this work is presented in the section 6 .

\section{MATERIALS AND METHODS}

\section{A. Study Area}

The study was carried out during the 2015 and 2016 campaigns on a citrus orchard located at the city of Gromabalia - Nabeul, Northeast of Tunisia (Long. $10.73^{\circ} \mathrm{N}$, Lat. $\left.36.45^{\circ} \mathrm{E}, \mathrm{E}: 0 \mathrm{~m}\right)$ in collaboration with the Technical Centre of Citrus (CTA), which is a governmental centre specialized in the promotion and development of the citrus industry. The region is characterized by a typical Mediterranean climate with five to six rainless months, an average annual precipitation of $460 \mathrm{~mm}$, falling mostly from November to March and a Thornwhite aridity index of 0.29 [6]. The experimented citrus orchard was planted in 1998 at $4 \times 5 \mathrm{~m}^{2}$ spacing. Trees are growing under standard conditions (disease-free, well-fertilized) and drip irrigated during the dry months (May-September, northern hemisphere) by using ten emitters by tree with a nominal discharge of $2.3 \mathrm{~L} \mathrm{~h}^{-1}$ emitter ${ }^{-1}$. Figure 1 shows the locations of the CTA and the weather station of Grombalia-Nabeul.

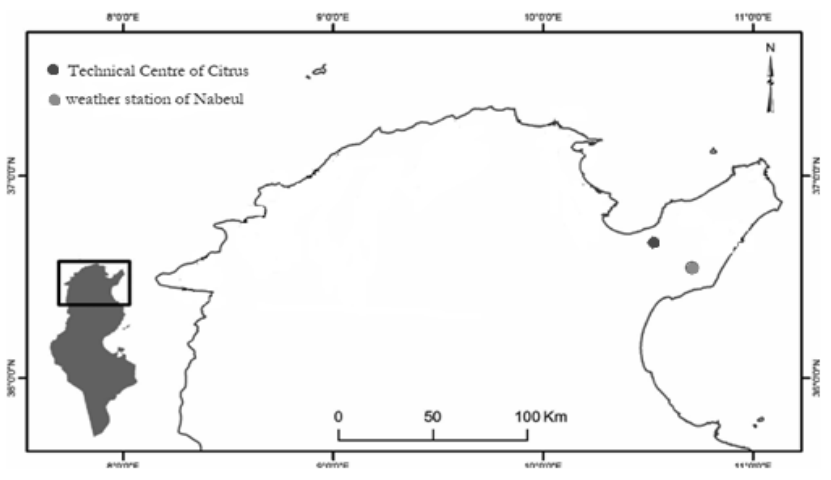

Fig.1. Locations of the Technical Centre of Citrus (site of experiment) and the weather station of Grombalia-Nabeul, Northeast of Tunisia.

\section{B. Climatic Data And Processing}

Table 1 presents the average climatic data observed during the period of the study.
Table 1: Study area specifications and mean climatic data for the 2015-2016 period.

\begin{tabular}{rllll}
\hline & $\mathrm{T}_{\min }$ & $\mathrm{T}_{\max }$ & $\mathrm{RH}_{\min }$ & $\mathrm{RH}_{\max }$ \\
\hline \multirow{2}{*}{$\begin{array}{c}\text { Station } \\
\text { CTA }\end{array}$} & {$[\mathrm{C}]$} & {$\left[{ }^{\circ} \mathrm{C}\right]$} & {$[\%]$} & {$[\%]$} \\
\cline { 2 - 5 } & 12.5 & 22.1 & 46 & 85 \\
\hline \multicolumn{5}{c}{} \\
\hline $\begin{array}{l}\text { Station } \\
\text { CTA }\end{array}$ & {$\left[\mathrm{m} \mathrm{s}^{-1}\right]$} & $\mathrm{S}_{\mathrm{ra}}$ & $\mathrm{P}$ \\
\cline { 2 - 5 } & 0.9 & {$\left[\mathrm{~W} \mathrm{~m}^{-2}\right]$} & {$[\mathrm{mm}]$} \\
\hline
\end{tabular}

To compute the crop evapotranspiration, two sets of hourly meteorological data (2015 and 2016) were used. The datasets of temperature $(\mathrm{T})$, relative humidity $(\mathrm{RH})$ (Figure 2), wind speed (Ws) (Figure 3), solar radiation (Sra) and precipitation (P), were obtained from the Centre Weather Station (CWS) and the flux tour of the selected field.

The database obtained from the CTA was subject to an outlier review using both, the automated and the manual procedures in order to remove the extreme values. The missing values were reconstituted by using the dataset of the flux tour and that recorded at the field's weather station. Then, the dataset was converted from hourly metrological records to daily metrological values. For air temperature and relative humidity, we have considered the daily maximum and minimum values. For precipitation we used the INM database to reconstitute the missing observations because only the weather station is equipped with a rain gauge. The final result is a new database (DB1) composed of 9 columns of daily variables: Date, $\operatorname{Tmin}\left[{ }^{\circ} \mathrm{C}\right]$ and $\mathrm{Tmax},\left[{ }^{\circ} \mathrm{C}\right]$ (Figure 4), RHmin [\%] and RHmax [\%] (Figure 5), Ws [m s-1] (Figure 6), Sra [W m-2] (Figure 7), P [mm] (Figure 8) and the actual irrigation amount IWr [L/tree/day] (Figure 9). All computations were made by using the software tool R.

The irrigation program (daily irrigation amounts applied to the citrus orchard of the CTA during the campaigns 2015 and 2016) was determined by the technical staff of the CTA, which used the FAO-56 Penman-Monteith method for ET0 computation. However, as water was scare during the last years, the government imposed severe restrictions, allowing the use of, only, a part of the available resources. Consequently, the amount of irrigation water supplied to the citrus trees (IWr) doesn't meet, systematically, the optimal crop water needs. These amounts are used for the 'learning' step of the MLFFNN.

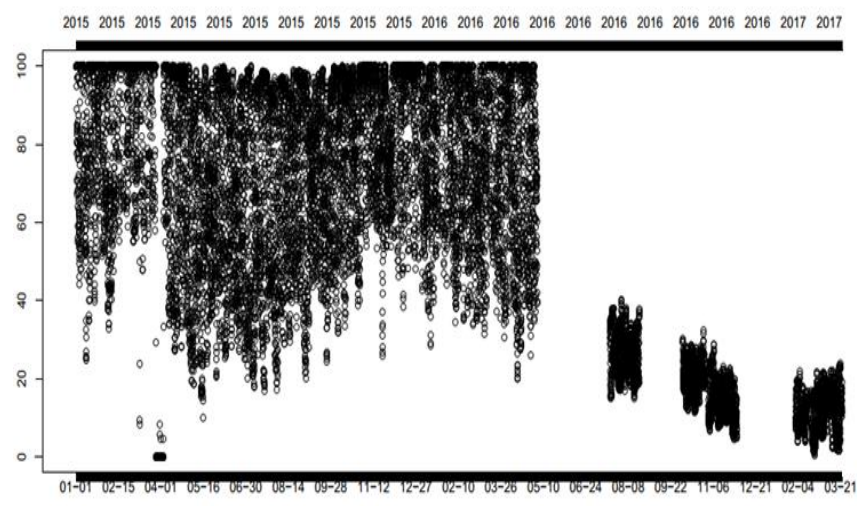

Date

Fig.2. Hourly relative humidity $(\mathrm{RH}, \%)$ recorded during the 2015-2016 period (Pre-processing) at the Centre Weather Station (CWS) and the flux tour of the selected field. 


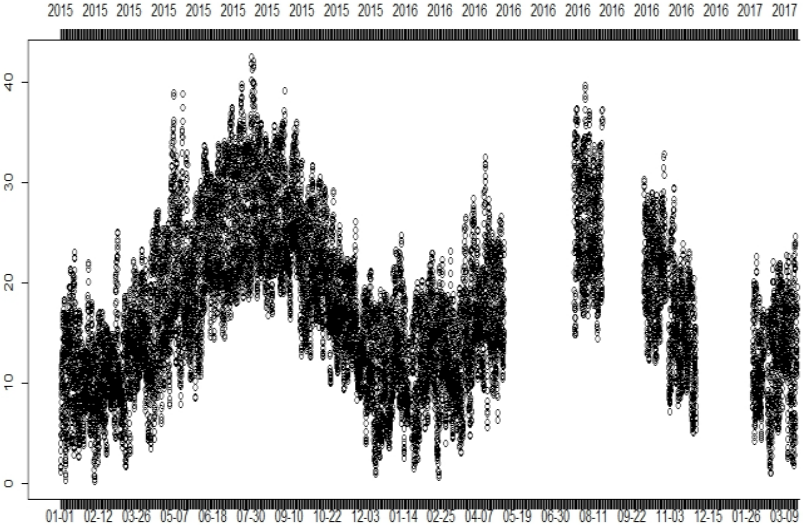

Fig.3. Hourly wind speed (WS, $\mathrm{m} \mathrm{s}^{-1}$ ) recorded during the 2015-2016 period (Pre-processing) at the Centre Weather 0

Station (CWS) and the flux tour of the selected field.

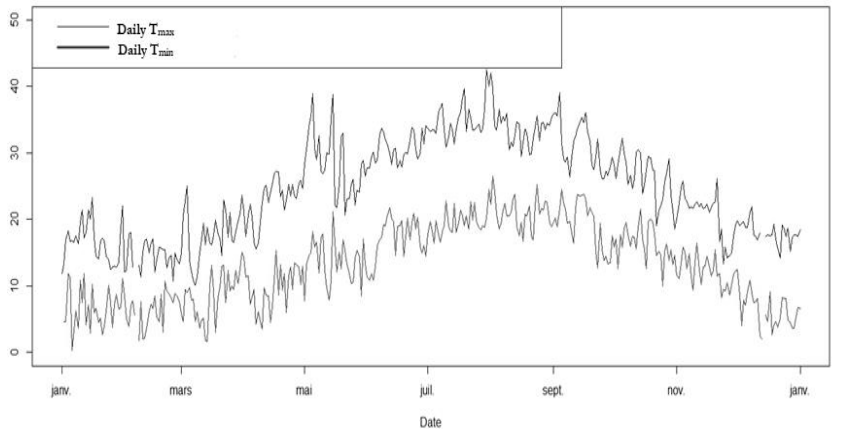

Fig.4. Daily $T_{\max }$ and $T_{\min }\left({ }^{\circ} \mathrm{C}\right)$ recorded in 2015 (Post-processing).

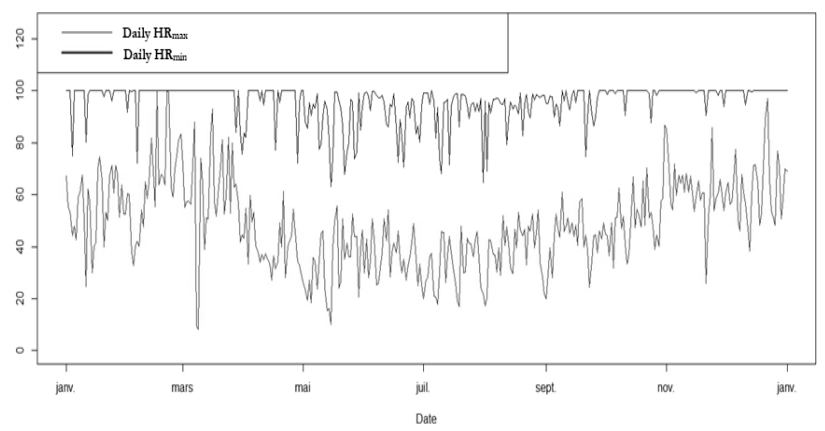

Fig.5. Daily $H R_{\max }$ and $H R_{\min }(\%)$ recorded in 2015 (Post-processing).

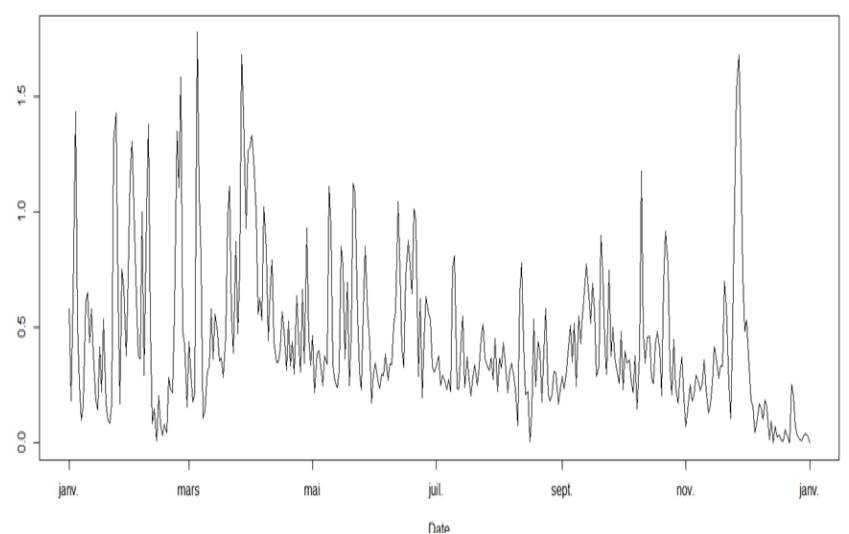

Fig.6. Daily $W_{s}\left(\mathrm{~m} \mathrm{~s}^{-1}\right)$ recorded in 2015 (Post-processing).

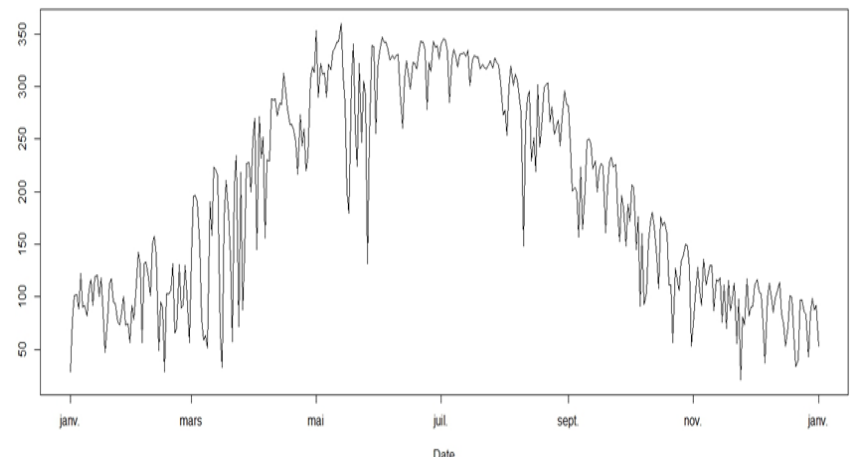

Fig.7. Daily $S_{r a}\left(W^{-2}\right)$ recorded in 2015 (Post-processing).

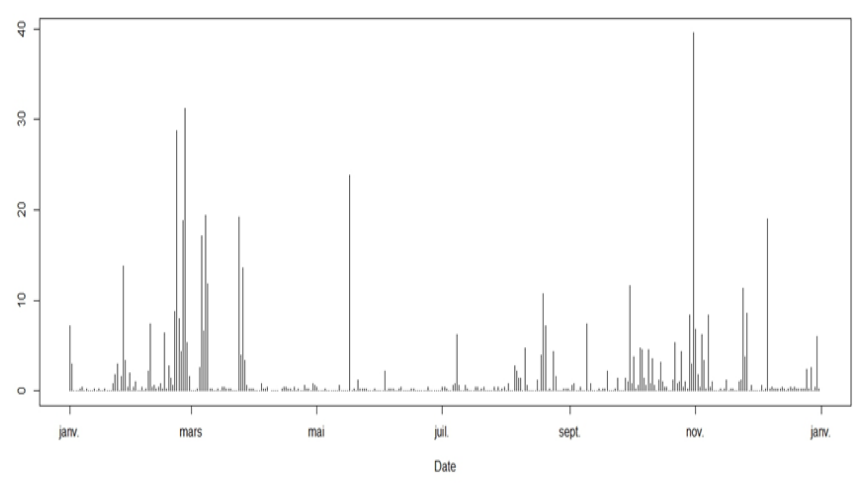

Fig.8. Daily $P$ (mm) amounts recorded in 2015 (Post-processing).

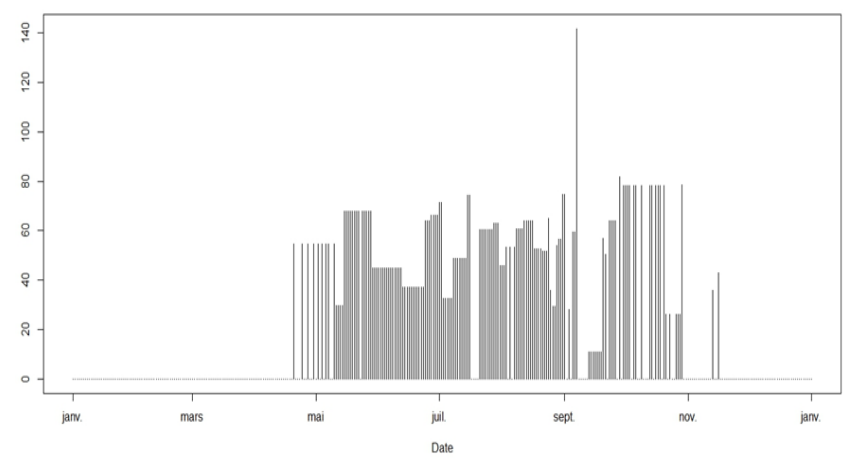

Fig.9. Daily irrigation water (IWr, L/tree/day) applied during the year 2015.

\section{Multi-Layer Feed Forward Neural Networks (MLFFNN)}

The Artificial Neural Networks (ANNs) is defined as a collection of highly connected elementary processors called neurons. Typically, neurons are organized in layers: input, hidden and output. These neurons are interconnected, i.e., each layer employs several neurons connected to the neurons of the other layers with different weights. The number of neurons in the hidden layer and the corresponding parameters are generally determined after assuming convergence of RMSE of the trial step. The signals flows into the input layer pass through the hidden layers and arrive at the output layer. During the training process, these weights can be adapted by using the Levenberg Marquardt algorithm LMA in order to generate the desired output, which is in the case of this study, the citrus water requirements.

For modelling the physical systems, the Multi-Layer Feed-Forward Neural Network (MLFFNN) is usually used. In 


\section{Intelligent Prediction of the Daily Irrigation Water Requirements for Citrus Orchards Using FFNN with Levenberg Marquardt Algorithm}

this network, each layer is fully connected to the preceding one. Figure 10 shows a typical MLFFNN containing two hidden layers, each with 5 neurons, using a sigmoid activation function. The output layer has a single neuron using a linear activation function.

The training of the network starts with random initialization of the weights and proceeds by iterant LMA in purpose to find the weights that optimize the RMSE, which is the chosen performance function for this study. The LMA ensures the adaptation of the learning rate $(\mu)$. In fact, $\mu$ is decreased after each successful step (reduction in RMSE) and it is increased only when a tentative step necessitate an increase of the RMSE. In this way, the RMSE will always be reduced at each iteration of the algorithm.

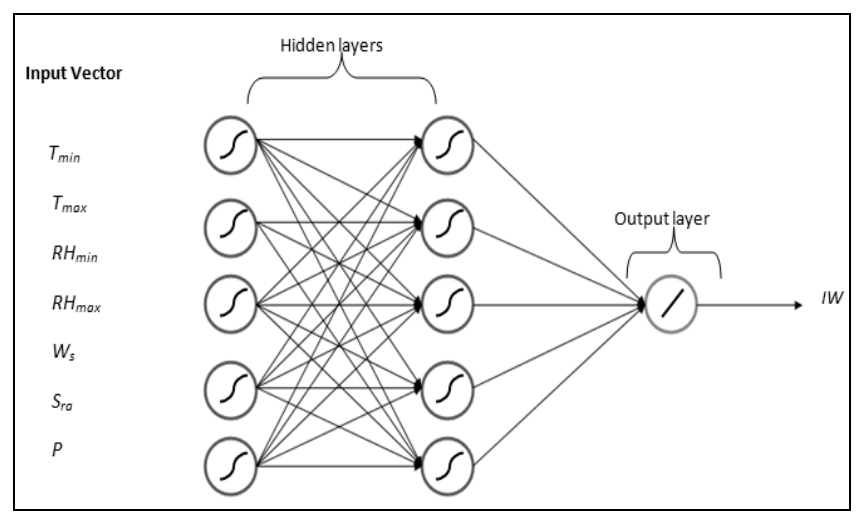

Fig.10. Architecture of the Feed Forward Neural Network [5 $51]$ using the following activation function \{logsig, logsig, purelin\}.

\section{Development of the MLFFNN}

\section{D.1 Choice of the Optimal MLFFNN Architecture}

The ANNs have many architectural forms and the choice of one of these architectures depends on the nature of the task to be performed. Several architectures are tested with the database (DB1) to establish the design of the MLFFNN model dedicated to predict the irrigation water amounts of the citrus orchard, considering the $2 / 3$ of the examples for the 'learning' step and the rest of the examples for the 'testing' step. The choice of these examples follows a certain order to give importance to the order of the seasons in the year. We assigned every two successive days to the 'training' set and the third day was attributed to the 'testing' set (DB1). It's essential to execute a normalization procedure before presenting the input data to the network. The input vector consists of seven climatic parameters Tmin , Tmax, , RHmin , RHmax , Ws , Sra , P and the desired output consists of one node, which is, in this case, the citrus water requirements.

The architecture A1 of the MLFFNN has two hidden layers, each with 5 neurons, using a sigmoid activation function and only one output layer with one neuron, using a linear activation function. The A1-MLFFNN is modeled by the combination [5 5 1] with the following activation function \{logsig, logsig, purelin\} (Figure 10). The architecture A2 of the MLFFNN has one hidden layer with 10 neurons using a sigmoidal activation function and an output layer with one neuron, only, using a linear activation function. The A2-MLFFNN is modelled by the combination [ 101 1] with the following activation function \{logsig, purelin\}. To develop this task, the code was written by using Matlab 7.12 programming language.
Both architectures (A1 and A2) provided low RMSE, with however some adjustment of the network's variables, which was made by increasing the number of iterations of the algorithm, adapting the synaptic weights and the learning rate $(\mu)$.

\section{D.2 Robustness of the designed MLFFN Network}

The database used (DB1) for the learning and the testing steps of both the A1 and the A2 networks does not take into account the periods of water shortage. Indeed, the data file received from the CTA contains the records relative to the available water during the irrigation period and of course the days when water was missing. For example in March 11, 2016, the irrigation process was interrupted due to a breakdown of the irrigation system. To overcome this problem, a new database (DB2) was created for the training MLFFNN by eliminating all these particular periods (breakdowns, water shortage, pump malfunction...) and in purpose to test the neural network, we used the whole database (DB1).

\section{SiMULATION RESULTS}

The A1-MLFFNN results are shown in Table 3, which are provided by using the DB1. Values showed that, for an adapted $\mu$ equal to 0.001 using LMA (with an initialised $\mu$ equal to $0.01(\mu \mathrm{i})$ ), the RMSE of the 'test' step decreases after 3000 epochs (Figure 11.a, Table 3). With the same A1-MLFFNN, results showed that for $\mu \mathrm{i}=0.002$, the RMSE of the 'testing' step is higher after 2000 epochs (Figure 11b, Table 3). For $\mu \mathrm{i}=0.01$, the A1-MLFFNN provided better results compared to the A2 MLFFNN structure for the 'test' step, although we used the same DB1 in the 'learning' step (Figure 11.a and Figure 11.c, Table 3).

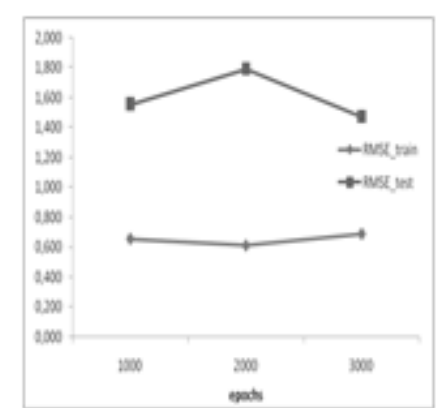

(a) (b)
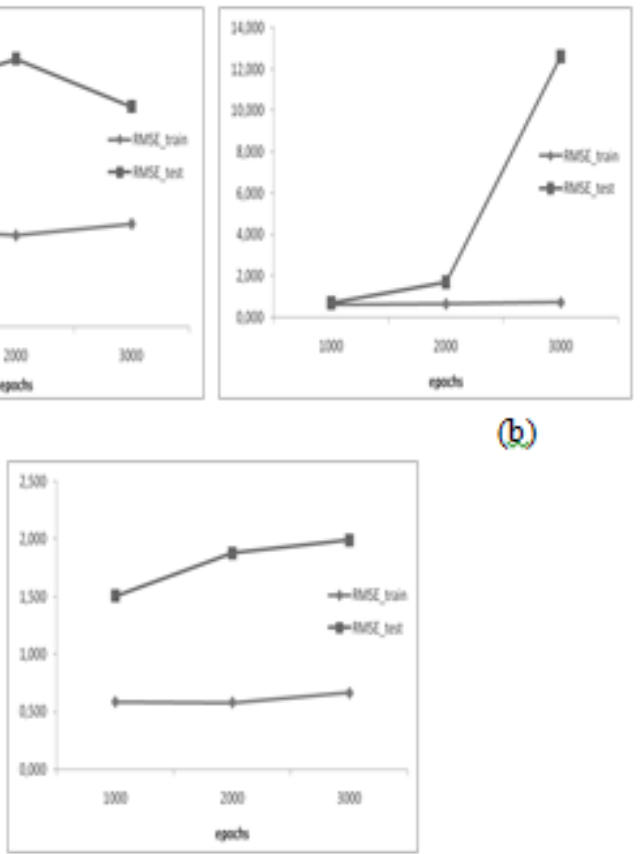

(c)

Fig.11. RMSE convergence curves for the 'learning' and the 'testing' steps using the DB1.

(a): Al-MLFFNN, $\mu=0.01$; (b): Al-MLFFNN, $\mu=0.002$; (c) A2-MLFFNN, $\mu=0.001$. 
The network A1-MLFFNN has been trained until 10000 epochs, using $\mu \mathrm{i}=0.01$. In this case, some samples in the 'testing' step showed wrong values of the irrigation water needs. Thus, the best choice is the network A1-MLFFNN trained with 1000 epochs; it provides the best estimation of the crop water needs (Figures 12 and 13). Values of RMSE obtained during the training and the test steps with A1-MLFFNN are 0.656 and 1.558 , respectively. The A1-MLFFNN using DB1 for learning and testing is named A1-MLFFNN/DB1. Figure 12 shows the A1-MLFFNN/DB1 outputs in the 'training' step while Figure 13 presents the A1-MLFFNN/DB1 outputs of the 'testing' step.

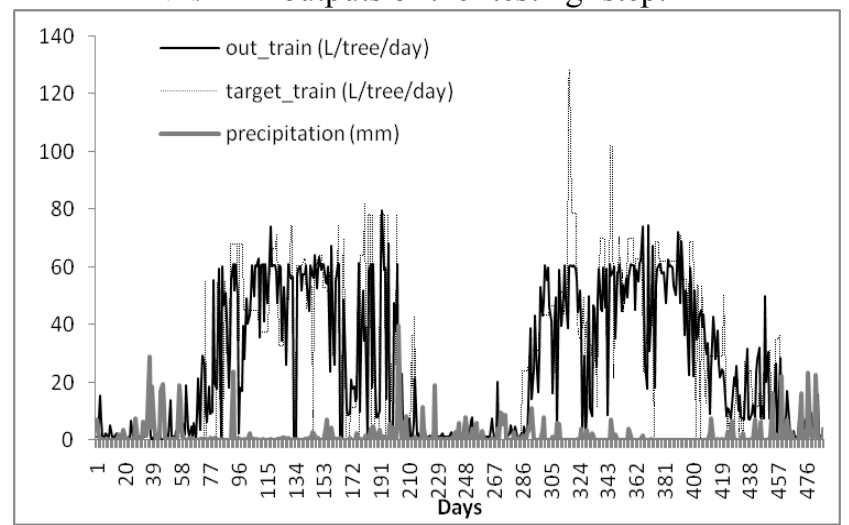

Fig.12. The A1-MLFFNN/DBloutputs in the training step. $\mu_{a}=0.0001,1000$ epochs.

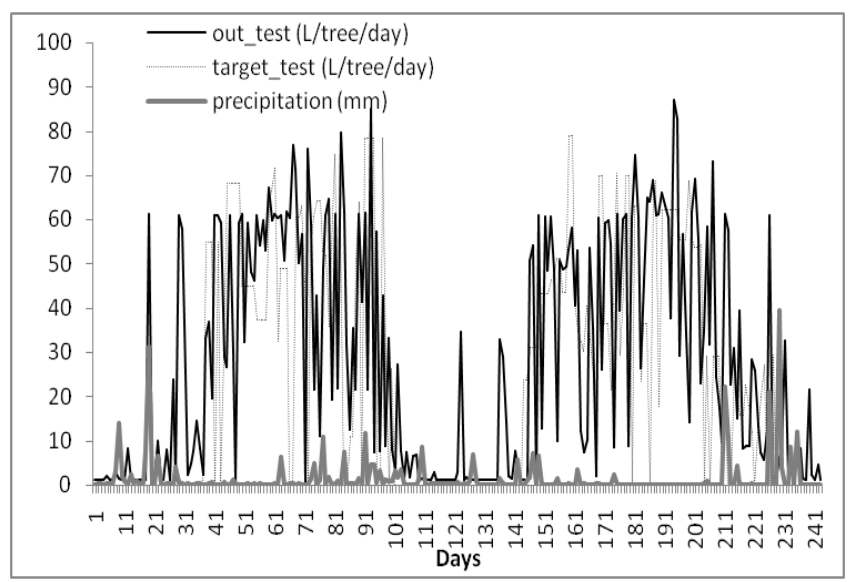

Fig.13. The A1-MLFFNN/DB1 outputs in the testing step.

\section{DISCUSSION}

\section{A. Robustness and Performance of the Optimal MLFFNN}

Considering the A1MLFFNN architecture when using the DB2 during the step of 'learning' with $\mu \mathrm{i}=0.01$ and after 1000 epochs, we have obtained $\mu \mathrm{a}=1 \mathrm{e}-06$. Here, it is interesting to note that the new neural network (A1-MLFFNN/DB2) has learned the period of the interruption of the irrigation process and it's able to meet rapid changes of the irrigation amounts (IWr). The RMSE obtained with A1-MLFFNN/DB2 during the training and the testing processes (using DB1 in test step) are 0.534 and 0.517 , respectively. The RMSE of the testing step with A1-MLFFNN/DB2 is lower compared to that obtained with A1-MLFFNN/DB1 (Table 3). This proves the robustness of the network A1-MLFFNN/DB2. Figure 14 shows the A1-MLFFNN/DB2 outputs in the training step with DB2, while Figure 15 presents the A1-MLFFNN/DB2 outputs in the testing step with DB1, with $\mu \mathrm{i}=0.01$ and 1000 epochs.

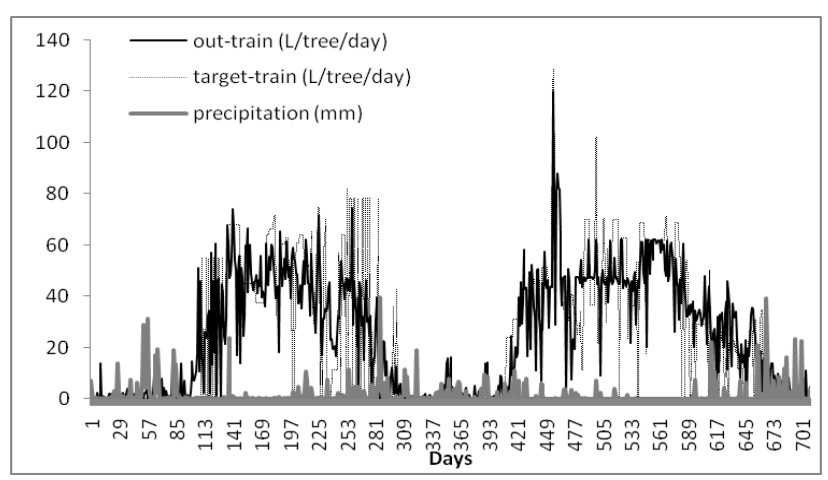

Fig.14. The A1-MLFFNN/DB2 outputs in the training step with $D B 2$.

In order to analyse the obtained results during the 'testing' step of the A1-MLFFNN/DB2 we have culled several samples (Figure 15 and Table 2):

- Mai 23, 2015 (day number in graph is 143): Breakdown of the electro-pumps. Although the intervention of CTA's personnel was $0 \mathrm{~L} /$ tree, the conceived A1-MLFFNN/DB2 estimates an amount of irrigation water of $46.94 \mathrm{~L} /$ tree as output. In view of the desired output during the day before and after the break down was $66.96 \mathrm{~L} /$ tree and $53.67 \mathrm{~L} /$ tree respectively.

Taking into account the absence of rain during these three successive days, we can consider that the estimated results of the A1-MLFFNN/DB2 are accurate.

- During the days: 7/25/2015, 8/2/2015 and 8/13/2015 (respectively days number in graph are: 206, 214 and 225), the CTA's personnel were obliged to compensate for the loss by increasing the amount of the irrigation water, but in the other hand the conceived A1-MLFFNN/DB2 generated lower values.

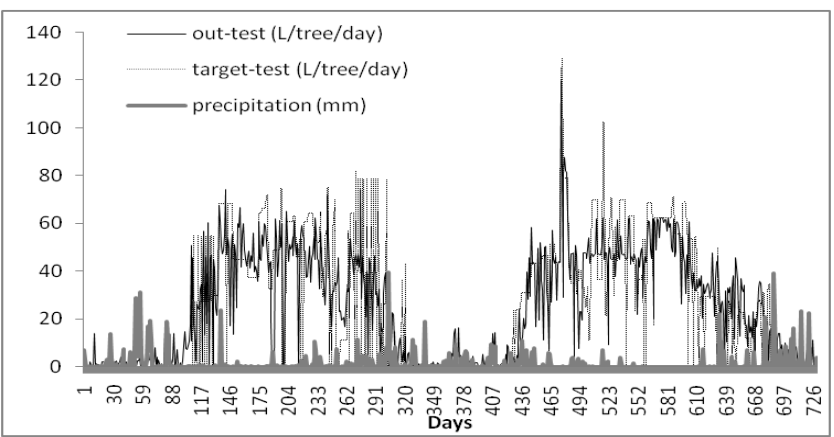

Fig.15. The A1-MLFFNN/DB2 outputs in the testing step with $D B 1$.

Table.2. Outputs of the A1-MLFFNN/DB2 in the 'testing' step compared to the corresponding target outputs for some particular cases when no precipitation occurs.

\begin{tabular}{cccc}
\hline Day number & $\begin{array}{c}\text { Out-test } \\
\text { (L/tree/day) }\end{array}$ & $\begin{array}{c}\text { Target-test } \\
(\text { L/tree/day })\end{array}$ & $\begin{array}{c}\text { Precipitation } \\
(\mathrm{mm})\end{array}$ \\
\hline 142 & 66.96 & 68.05 & 0.2 \\
\hline 143 & 46.94 & 0 & 0.2 \\
\hline 144 & 53.67 & 68.05 & 0.2 \\
\hline 206 & 49.33 & 60.44 & 0 \\
\hline 214 & 0 & 45.82 & 0.8 \\
\hline 225 & 50.48 & 64.07 & 0
\end{tabular}




\section{B. Performances and Confrontations}

The results show that the A1-MLFFNN/DB2 is the most efficient in terms of RMSE (Table 3), although we have to pre-treat the database by eliminating the problematic days, which makes the procedure non-automatic.

Table.3. Performance of the different MLFFNN architectures used for the training step.

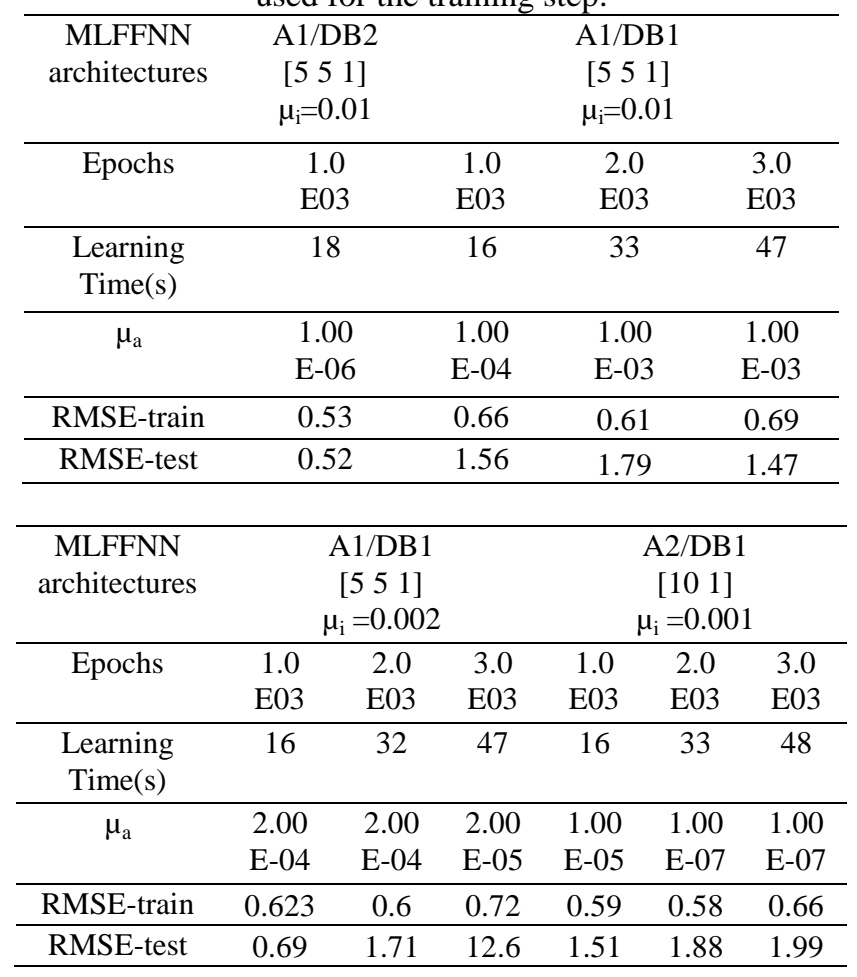

The networks A1-MLFFNN/DB1 and A1-MLFFNN/DB2 are the fastest in the 'learning' step (Table 3 ) and have a lower level of complexity (number of neurons) than other networks cited in the literature such as the Second Order Neural Network (SONN) and the Back Propagation Neural Network (BPNN) [1]. It is slightly less efficient than the last ones because the authors Adamala et al. (2014) use 5 successive years of data and in our case the database is limited to two consecutive years, only. The designed networks are less complex in their implementation than those used by Adamala et al. (2014), because:

1) These authors used 10 distributed neurons with equal numbers for the two layers, unlike other methods which use a greater number of neurons for a single layer; this makes the calculation procedure longer.

2) The learning rate used in our study is adapted automatically by the LMA, which is not the case for the SONN and BPNN methods; the value of the rate is changed manually following the RMSE test results.

\section{VALIDATION}

Correlations established between the amounts of water (IWr) supplied to the citrus trees by the CTA and those estimated by the two neuronal architectures A1-MLFFNN / DB1 and A1-MLFFNN / DB2 showed high correlative coefficients of 0.596 and 0.799 , respectively (Figures 16 and 17). These results confirm the previous one (lower RMSE error with the A1-MLFFNN/DB2 model) and show the superiority of the A1-MLFFNN/DB2 model comparatively to the A1-MLFFNN/DB1 one.

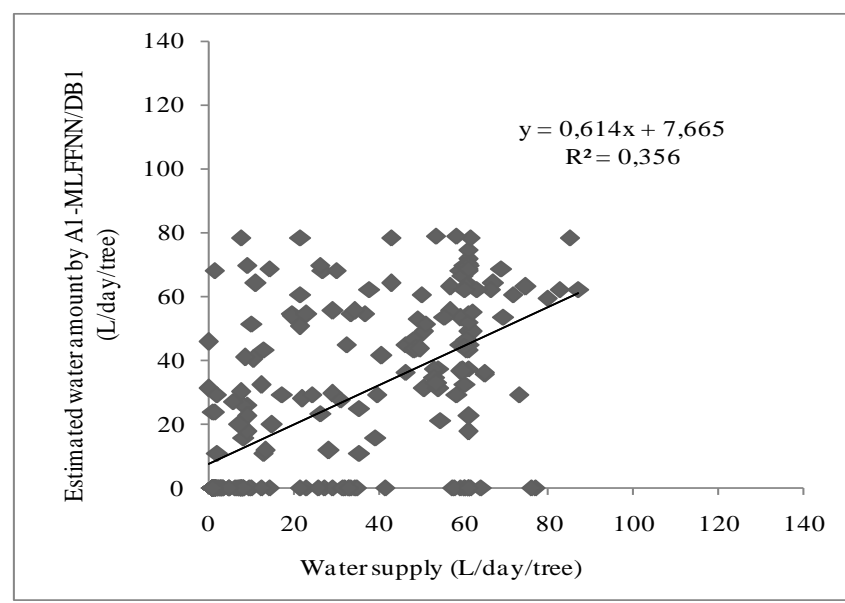

Fig. 16. Correlation between the amount of water supplied to the citrus trees and those estimated by the A1-MLFFNN/DB1. Amounts are given in L/day/tree.

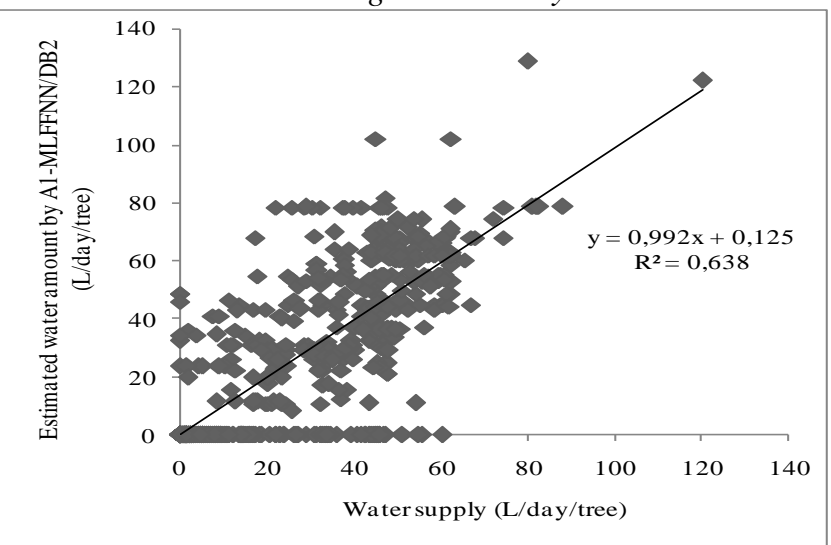

Fig.17. Correlation between the amount of water supplied to the citrus trees and those estimated by the A1-MLFFNN/DB2. Amounts are given in L/day/tree.

\section{CONCLUSION}

In this paper, the Multi Layer Feed Forward Neural Network MLFFNN using the Levenberg-Marquardt algorithm have shown it's performances to well predict the citrus water requirements. It is established that the smart architecture (5-5-1) of the MLFFNN is capable to generate acceptable results compared to the models cited in the literature: Second Order neural network (SONN) and Back Propagation Neural Network (BPNN). These latest uses a greater number of neurons, making the spend time in the learning step longer. Validation of the neuronal architectures A1-MLFFNN / DB1 and A1-MLFFNN / DB2 showed distinctly the superiority of the A1-MLFFNN / DB2 architecture in estimating the amounts of water needed by the olive trees. Indeed, with the A1-MLFFNN / DB2 we have obtained higher correlative coefficients than that obtained with the A1-MLFFNN / DB1.

In the future, we plan to use a larger database for the training and the validation of the MLFFNN which will lead us to remove some idealizations used in this paper and extend this application to other orchards grown under more restricted conditions (diseases, water shortage...).

\section{ACKNOWLEDGMENT}

Authors would like to thank the CTA's and the National Institute of Researchers in Rural Engineering, Water and Forests' personal for their assistance. 


\section{REFERENCES}

[1] S. Adamala, N.S. Raghuwanshi, A. Mishra, M.K. Tiwari, Evapotranspiration modelling using second-order neural networks. J. Hydrol. Eng., 2014, 19(6), pp:1131-1140.

[2] R.G. Allen, L.S. Pereira, D. Raes, M. Smith, Crop Evapotranspiration: Guidelines for Computing Crop Water Requirements. United Nations Food and Agriculture Organization, Irrigation and Drainage Paper 56, Rome, Italy, 1998. p 300.

[3] R.G. Allen, W.O. Pruitt, J.L. Wright, T.A. Howell, F.Ventura, R. Snyder, D. Itenfisu, P. Steduto, J. Berengena, J. Baselga, M. Smith, L.S. Pereira, D. Raes, A. Perrier, I. Alves, I. Walter, R. Elliott, A Recommendation on Standardized Surface Resistance for Hourly Calculation of Reference ETO by the FAO 56 PM-Method. Agricultural Water Management, 2006, Vol.81: pp:1-22, [Online]. Available: http://dx.doi.org/10.1016/j.agwat.2005.03.007.

[4] H. Habaieb, C.Masmoudi-Charfi, Calcul des besoins en eau des principales cultures exploitées en Tunisie: Estimation de l'évapotranspiration de référence par différentes formules empiriques. Cas des régions de Tunis, Béja et Bizerte, Sécheresse, 2003, Vol.14, pp :1-9.

[5] M. Kumar, N.S. Raghuwanshi, R. Singh, W. Wallender, W.O. Pruitt, Estimating evapotranspiration using artificial neural network. J. Irrig. Drain. Eng., 2002, Vol.128 (4), pp:224-233.

[6] C. Masmoudi-Charfi, H. Habaieb, Rainfall Distribution Functions for Irrigation Scheduling: Calculation procedures following the site of olive (Olea europaea L.) cultivation and growing periods, American Journal of Plant Sciences, 2014, Vol.5, pp:2094-2133. [Online]. Available: http://dx.doi.org/10.4236/ajps.2014.513224.

[7] A. Rahimikhoob, Estimation of evapotranspiration based on only air temperature data using artificial neural networks for a subtropical climate in Iran. Theor. Appl. Climatol., 2010, Vol.101(1-2), pp:83-91.

[8] G. Rana, N.Katerji, Measurement and Estimation of Actual Evapotranspiration in the Field under Mediterranean Climate: A Review, European Journal of Agronomy, 2000, Vol.13, pp:125-153 [Online].Available:http://dx.doi.org/10.1016/S1161-0301(00)000708.

[9] T.W. Sammis, J. Wang, D.R. Miller, The Transition of the Blaney-Criddle Formula to the Penman-Monteith Equation in the Western US, Journal of Service Climatology, 2011, Vol.5, pp:1-11, [Online]. Available: www.journalofserviceclimatology.org

[10] M. Smith, R.G. Allen, L.S. Pereira, Revised FAO methodology for crop water requirements. In: Camp, C.R., Sadler, E.J., Yoder, R.E. (Eds.). Evapotranspiration and Irrigation Scheduling. ASAE, San Antonio, TX, 1996, pp.116-123.

[11] S.S. Zanetti, E.F. Sous, V.P.S. Oliveira, F.T. Almeida, S. Bernardo, Estimating evapotranspiration using artificial neural network and minimum climatological data. J. Irrig. Drain. Eng, 2007, Vol.133:2 (83), pp:83-89.

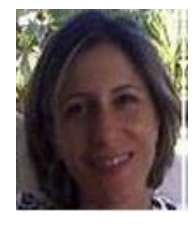

Dr. Olfa Marrakchi Charfi was born in Tunis, Tunisia, in 1968. She received the M.S. and Ph.D. degrees in electrical engineering, in Telecoms speciality, from the National School of Engineering of Tunis (ENIT), in 1995 and 1999, respectively. In 2000, she joined the National Institute of Applied Sciences and Technology of Tunis, where she is presently an Associate Assistant. During 1994-1999, she was with the Spatial Reference Systems and Remote Sensing Laboratory of ENIT. From 2003 to 2012, she was with Laboratory of Systems and Signal Processing of ENIT. Since 2015 she has joined the Natural Resources Management Laboratory of National Institute of Agronomy of Tunis (INAT), specialized in spatial detection, spatial analysis and modeling "GREEN-TEAM Laboratory", and she is interested in the characterization of arboreal surfaces and moisture soils using satellite data, in optics and in radar domains. Her research interests include image processing, learning machines, textures analysis, discrete wavelet transform (DWT) and applications of signal processing to remote sensing (RS). Currently, her research emphasis is on RS textures characterization and RS data classification, neural network and support vector machines algorithms.

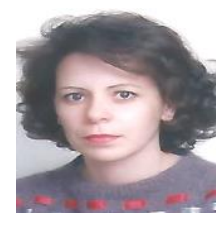

Chiraz Masmoudi Charfi was born in 1965 in Tunis (Tunisia). Researcher, Assistant Professor at the Olive Institut. Agricultural Engineer Specialized in Horticulture (National Agricultural Institute of Tunisia INAT, 1992). Doctor of State in Agronomy (INAT 1998) Holder of the Diploma of Advanced Studies in Plant Physiology (Faculty of Sciences of Tunis 1997).
Prize of the Tunisian Association of Horticultural Sciences (1992). Oleiculture specialist. Current research topic water management in olive plantations. Involved in national and international research projects: DIMAS / 2004/2008 (Contract n ${ }^{\circ}$ INCO-CI-2004-509087) / Bilateral Cooperation and Research Exchange Project Tunisia-Portugal (1999) / Tuniso-Belgian project INAT / CGRE (1998/1999). Participation in 15 courses (internships in Tunisia-Portugal-Belgium and Spain) and animation of several training courses for young promoters and technical staff of the Ministry of Supervision. Publication of 30 articles, indexed and impacted journals, 5 book chapters (Eds Nova Sci Publishers NY) (All published on ResearchGate and Google Scholar HI = 7), 9 technical papers, 35 national and international oral papers and numerous posters (National and International Fairs). Evaluator of scientific articles (20 manuscripts for Scientia Horticultuae, Plant Physiology and 12 journals of Science Domain International with certificates), 5 research proposals (Tunisian-German cooperation and AQP project) and 3 theses. Good command of Arabic, French and English, spoken and written. Mastery of current software (Word, Excel, Power Point) and CropWat and AquaCrop6.1-2018 water management. Field experience: 15 years. Assistance to olive growers and development of 17 studies for the establishment and management of olive plantations.

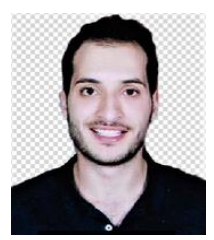

Nizar Louhichi was born in Tunis, Tunisia in 1994. He received the M.S degree in Industrial Computing and Control engineering from the National Institute of Applied Science and Technology (INSAT) in October 2017. During his graduation project, he joined the National Institute of Rural Engineering Research, Water and Forestry (INRGREF) with the collaboration of the company Waycon- Distributor and integrator of electronic solutions, where he has been creating and maintaining a model based on a feed-forward neural network to predict daily irrigation water requirements for citrus orchards in North-East region of Tunisia. Just after graduation he was recruited by a French IT start-up, he have been undertaking several projects such as application development to manage the company and conducting research work about infrastructures for high performance computing (Distributed systems, Cluster computing). Furthermore he participated in recruiting and building a team of five trainees and he managed the good proceedings of their respective projects. For now he is starting a new position as a DevOps engineer at ESI Group. 